\title{
Desafios da prática do acolhimento de surdos na atenção primária
}

\author{
Challenges for receiving hearing-impaired \\ individuals in primary healthcare services
}

\author{
Desafíos de la práctica de acogida de sordos en \\ la atención primaria
}

\begin{abstract}
${ }_{1}^{1}$ Universidade do Vale do Rio dos Sinos, São Leopoldo, Brasil.

2 Secretaria Municipal de Saúde de Dois Irmãos, Dois Irmãos, Brasil.

Correspondência

$J$. R. Junges

Universidade do Vale do Rio

dos Sinos.

Av. Unisinos 950, São

Leopoldo, RS

93022-000, Brasil.

roquejunges@hotmail.com
\end{abstract}

\section{Abstract}

Health services should properly receive and establish bonds with patients in order to ensure user access and reorganization of care. Users with special needs require specific attention, especially individuals with hearing disabilities, whose needs pose a particular challenge, since "dedicated listening" involves a potential language barrier. This study was conducted in the Community Health Centers of the Conceição Hospital Group, a Federal public institution integrated with the primary care system in Porto Alegre, Rio Grande do Sul State, Brazil. A qualitative approach used semi-structured interviews with 12 health professionals, the Community Health Coordinator, and the Advisory Department for Users with Special Needs. The results showed that health professionals test different approaches to deal with difficulties in communicating with hearing-impaired patients, and that the professionals' overall attitude revealed their discomfort and lack of training for dealing with the needs of patients with hearing disabilities.

Health Services Accessibility; User Embracement; Hearing Impaired Persons; Primary Health Care
Janaina dos Reis Tedesco 1,2 José Roque Junges 1

\section{Resumo}

O acolhimento e vínculo são fundamentais para o acesso e a reorganização das ações. Os portadores de necessidades especiais exigem uma atenção específica, principalmente os portadores de surdez que apresentam maior desafio no acolhimento de suas necessidades, porque a "escuta qualificada" apresenta a barreira da linguagem. A pesquisa foi realizada nos Postos de Saúde Comunitária do Grupo Hospitalar Conceição, instituição pública federal em Porto Alegre, Rio Grande do Sul, Brasil, integrada na atenção primária do município. Foi utilizada a abordagem qualitativa com entrevistas semiestruturadas com 12 profissionais, com a Coordenadora da Saúde Comunitária e a coordenação da assessoria no atendimento a usuários com necessidades especiais. Os resultados evidenciaram que os profissionais buscam diferentes ferramentas para obviar a dificuldade da comunicação com os surdos, e que a postura dos profissionais em geral manifesta desconforto e despreparo para atender às necessidades dos portadores de surdez.

Acesso aos Serviços de Saúde; Acolhimento; Pessoas com a Deficiência Auditiva; Atenção Primária à Saúde; 


\section{Introdução}

O acolhimento está baseado no estabelecimento de relações solidárias e de confiança entre os profissionais e as pessoas que procuram os serviços, para resolver seu problema de saúde, tornando-se aspecto importante para que ocorra o vínculo, contribuindo para a resolubilidade do problema 1

Ao acolher, são mobilizados os aspectos das relações que se estabelecem no âmbito do atendimento para que aconteça o direito à saúde, base para a consciência cidadã. O momento do acolhimento na atenção básica à saúde compõe um potencial cenário para conflitos éticos no dia a dia das ações ${ }^{2}$. Nesse contexto, acolher as necessidades em saúde de pessoas portadoras de deficiência significa um desafio aos profissionais.

Em 2006, foi lançada a Política Nacional de Saúde da Pessoa Portadora de Deficiência 2, em que são assegurados os seus direitos. Os usuários portadores de deficiência auditiva se deparam com uma dificuldade acrescida, devido ao problema da comunicação interpessoal, pois no momento de acolhida o usuário surdo precisa comunicar sua necessidade e ser orientado quanto à conduta a ser seguida.

O Decreto Lei no 5.626 de 2005, que garante o direito à saúde das pessoas surdas ou com deficiência auditiva determinando que, a partir de 2006, seja organizado o atendimento às pessoas com deficiência auditiva na rede de serviços do SUS 3 .

Os pacientes surdos buscam o sistema de saúde com menos frequência que os pacientes ouvintes, referindo, como principais dificuldades, o medo, a desconfiança e a frustração 4 .

Durante o acolhimento dos usuários pelos profissionais da saúde, é necessário que se estabeleça uma forma de comunicação que possibilite o entendimento. Na maioria das vezes, essa comunicação se dá usando-se a linguagem verbal. Mas existem outras formas de comunicação, como a LIBRAS, que é a língua oficial utilizada pela população surda brasileira, reconhecida como meio legal de comunicação e expressão.

O Grupo Hospitalar Conceição (GHC), uma instituição pública federal de atendimento dos três níveis de atenção, que preocupado com a mobilidade e acessibilidade de portadores de deficiência, criou no ano de 2005 a Comissão Especial de Políticas de Promoção da Acessibilidade e da Mobilidade (CEPPAM) com o objetivo de refletir, propor, assessorar e acompanhar as políticas de inserção das pessoas portadoras de deficiência.

Diante desse cenário, este trabalho tem o objetivo de apontar os desafios que os profissio- nais da saúde comunitária do GHC vivenciam no atendimento aos usuários surdos.

\section{Metodologia}

Estudo de abordagem qualitativa, de caráter exploratório-descritivo que utilizou, para coleta de dados, entrevistas com profissionais do GHC: um membro da Coordenação do CEPPAM; a Coordenadora e 12 profissionais da saúde comunitária. As entrevistas tiveram como roteiro duas questões: (1) conhecimento sobre a política de acessibilidade e mobilidade de pessoas com deficiência; e (2) como acontece o atendimento de pessoas surdas no dia a dia das unidades.

As entrevistas foram gravadas e interpretadas segundo a análise temática, transformando os pontos relevantes em unidades de registro codificadas em categorias.

A pesquisa foi aprovada pelo Comitê de Ética do GHC, e para preservar a confidencialidade os nomes dos entrevistados foram substituídos por nomes de flores.

\section{Resultados e discussão}

Com base na análise do conteúdo duas categorias ficaram evidentes: (1) ferramentas de comunicação com o usuário surdo; e (2) postura na comunicação com o usuário surdo.

\section{Ferramentas de comunicação com o} usuário surdo

Sobre o atendimento às pessoas surdas, os entrevistados relatam que ferramentas utilizam na comunicação. Os meios utilizados no atendimento foram: a comunicação escrita; a presença de um familiar ou acompanhante; e o uso de gestos.

Alguns entrevistados citam a comunicação escrita como ponto fundamental para que ocorra a comunicação.

“...A gente escreve, por sinais, mas não a linguagem deles... Ela sabe ler então isso já ajuda bastante, porque daí tu se comunica..." (Amorperfeito).

É comum a população surda ter menos instrução que a população em geral. Esses necessitam de maior atenção e cuidados quando são utilizados termos técnicos, evitando palavras que possam levar a confusões e lembrando a necessidade de utilizar letra legível. É necessário ter presente que as pessoas surdas comunicam-se usando a LIBRAS, que tem gramática e vocabulário diferentes da língua portuguesa 5 . 
Durante as entrevistas os profissionais também consideraram a presença de um familiar, de um acompanhante do usuário surdo como importante para que ocorra o atendimento. Esse faz uma "tradução", como se nota nas seguintes falas.

“...Ele é acompanhado na unidade, ele tem acesso, só que normalmente ele vem acompanhado de um familiar..." (Violeta).

“...Assim, o acompanhante a entende, ele vem junto e traduz pra nós o que ela está tentando dizer..." (Azaleia).

Ao depender de outras pessoas para acessar os serviços e informações de saúde, a cidadania dos surdos fica prejudicada 6 . Uma barreira imposta aos surdos e profissionais é não compartilharem a mesma linguagem. $\mathrm{O}$ atendimento igualitário na área da saúde não é garantido ao surdo, embora seja brasileiro e da mesma cultura das pessoas ouvintes 7 .

Ainda aparece a importância de ter um profissional de referência na unidade de saúde para a população surda.

"Nós temos uma funcionária que fez curso de Libras, ela fica mais designada para estas situações assim" (Copo-de-leite).

Em estudo realizado para conhecer as necessidades de saúde dos surdos 8 , pontua-se as dificuldades enfrentadas ao procurarem os serviços, sendo a principal delas a comunicação. Citam-se como propostas, um intérprete em LIBRAS ou profissionais que saibam se comunicar nesta língua.

Geralmente, os surdos utilizam gestos e expressões que não pertencem à LIBRAS, mas que são entendidas universalmente como expressões de dor, apontar o local para auxiliar quem o está atentendo. O profissional deve atentar para os sinais usados, e se não entender perguntar novamente 5 .

\section{A postura na comunicação com o usuário surdo}

Sobre o atendimento às pessoas com surdez, muitos entrevistados referiram algumas posturas.

"Já tive contato. Pra mim é uma dificuldade. Eu não peguei nem um analfabeto. A minha sorte. ...Eu ficava mais angustiado..." (Boca-de-leão).

"Desculpa, mas eu presencio pessoas falando alto, tentando se comunicar desta forma, acho que gera ansiedade" (Copo-de-leite).

A linguagem utilizada pelos surdos foi comparada pelos entrevistados como uma língua estrangeira. Essa postura fica evidenciada nas falas a seguir.

"A linguagem do surdo é como ir para outro país, se fala através de gestos, quando não tem ninguém que possa interpretar..." (Margarida).
Nas entrevistas, ficou evidente que os profissionais sentem-se desconfortáveis ao atender pessoas surdas. Referiram o sentimento de ansiedade e de angústia como fatores presentes durante os atendimentos. Esses sentimentos surgem porque se sentem despreparados para um atendimento não comum.

Diante das dificuldades ficou evidenciada a necessidade de uma postura de disponibilidade e dedicação.

“...O profissional tem que estar muito disponível, não pode ir cheio de dedos. Disponível para utilizar outras linguagens, na relação com estas pessoas..." (Bromélia).

Foi também referida a busca de aperfeiçoamento por meio de cursos e capacitações.

"Acho que qualquer profissional pode se habilitar para trabalhar com essa população... a gente se beneficia dos treinamentos..." (Copo-de-leite).

Em pesquisa sobre o acesso dos surdos aos serviços de atenção básica em São Paulo, relatase que os gerentes, não sabendo os caminhos a serem traçados para a melhoria deste tipo de acesso, reconhecem a falta de discussão e problematização do tema e a necessidade da promoção do acesso da comunidade surda à rede de atenção básica de saúde 9 .

Autores apontam o acolhimento como a diretriz operacional fundamental para a inversão do modelo técnico-assistencial no SUS, por meio da garantia da acessibilidade universal e a qualificação das relações 10 .

Teixeira ${ }^{11}$ considera que o trabalho em saúde possui uma natureza eminentemente conversacional. Assim, o cuidado dialogado só é possível entendendo a conversa como um instrumento do acolhimento e organizando o serviço como uma rede de conversações. Essa constatação é fundamental para o atendimento qualificado do usuário surdo.

Considerando o acolhimento, uma ferramenta importante para a qualificação das relações e processos no SUS deve refletir sobre como se pode ter uma atitude de escuta qualificada e como reorientar o serviço.

\section{Considerações finais}

Se o acolhimento compreende ao mesmo tempo ferramentas adequadas de comunicação e postura ética de escuta qualificada, os resultados da pesquisa demonstram que existem deficiências no acolhimento. Por isso, a comunicação não utiliza ferramentas adequadas para o usuário surdo, lançando mão de substitutivos que não possibilitam uma verdadeira escuta qualificada e, por fim, o despreparo para essas situações 
provoca angústia e ansiedade nos profissionais, impedindo uma atitude verdadeira de diálogo e acolhimento. Essa constatação aponta para a necessidade de introduzir esse tema na educação permanente, a fim de capacitar os profissionais e reorientar os serviços para a escuta qualificada das necessidades dos usuários surdos.

\section{Resumen}

Las directrices de universalidad, integridad y equidad, acogida y vínculo son fundamentales para la calidad de los servicios de salud. Los portadores de sordera representan un desafío especial para la atención en salud. La investigación ha sido realizada en los servicios de salud comunitarios del Grupo Hospitalario Concepción en Porto Alegre, integrada en la atención primaria del municipio. Se utilizó un enfoque cualitativo con entrevistas a 12 profesionales, con la coordinadora general de salud comunitaria y en coordinación con la comisión para la atención de necesidades especiales Los resultados evidenciaron que los profesionales buscan diferentes herramientas para superar las dificultades de comunicación de los sordos; que la postura de los profesionales manifiesta en general disconformidad $y$ falta de preparación para atender las necesidades de los portadores de sordera.

Accesibilidad a los Servicios de Salud; Acogimiento;

Personas con Deficiencia Auditiva; Atención

Primaria de Salud

\section{Colaboradores}

J. R. Tedesco foi responsável pela coleta de dados, análise e redação do artigo. J. R. Junges contribuiu na análise e redação do artigo.

\section{Agradecimentos}

A autora principal, J. R. Tedesco, agradece à pesquisadora Lisiane Andréia Denivar Périco, orientadora da pesquisa que deu origem a este artigo, e à Lidiane Barazzetti, responsável pela formatação do artigo nas normas da revista. Um agradecimento especial aos profissionais da atenção primária do Grupo Hospitalar Conceição por sua prontidão e interesse em participar da pesquisa. 


\section{Referências}

1. Ministério da Saúde. Humanização da atenção à saúde. http://dtr2004.saude.gov.br/susdeaz/topi cos (acessado em 10/Nov/2006).

2. Ministério da Saúde. Política nacional de saúde da pessoa portadora de deficiência. http://portal. saude.gov.br (acessado em 15/Set/2007).

3. Brasil. Decreto no 5.626. Regulamentação da língua brasileira de sinais - libras. http://www.pla nalto.gov.br/ (acessado em 10/Mar/2012).

4. Steinberg AG, Barnett S, Meador HE, Wiggins EA, Zazove P. Health care system accessibility. Experiences and perceptions of deaf people. J Gen Intern Med 2006; 21:260-6.

5. Cardoso AHA, Rodrigues KG, Bachion MM. Percepção da pessoa com surdez severa e/ou profunda acerca do processo de comunicação durante seu atendimento de saúde. Rev Latinoam Enferm 2006; 14:553-60.

6. Casate JC, Corrêa AK. Humanização do atendimento em saúde: conhecimento veiculado na literatura brasileira de enfermagem. Rev Latinoam Enferm 2005; 13:105-11.
7. Chaveiro N, Barbosa MA. Assistência ao surdo na área de saúde como fator de inclusão social. Rev Esc Enferm USP 2005; 39:417-22.

8. Santos EM, Shiratori K. As necessidades de saúde no mundo do silêncio: um diálogo com os surdos. Rev Eletrônica Enferm 2004; 6:68-76.

9. Ianni A, Pereira PCA. Acesso da comunidade surda à rede básica de saúde. Saúde Soc 2012; 18 Suppl 2:89-92.

10. Franco TB, Bueno WS, Merhy EE. O Acolhimento e os processos de trabalho em saúde: o caso de Betim (MG). In: Merhy EE, Magalhães Júnior EM, Rimoli J, Franco TB, Bueno WS, organizadores. O trabalho em saúde: olhando e experienciando o SUS no cotidiano. 2a Ed. São Paulo: Editora Hucitec; 2004. p. 37-54.

11. Teixeira RR. Humanização e atenção básica. Ciênc Saúde Coletiva 2005; 10:585-97.

Recebido em 20/Nov/2012

Versão final reapresentada em 05/Abr/2013

Aprovado em 25/Abr/2013 